J. Amer. Soc. Hort. ScI. 117(6):906-912. 1992.

\title{
Soluble Silicon Sprays Inhibit Powdery Mildew Development on Grape Leaves
}

\author{
Pat Bowen ${ }^{1}$ Jim Menzies', and David Ehret ${ }^{1}$ \\ Research Station, Agriculture Canada, P. O. Box 1000, Agassiz, B. C. VOM 1A0, Canada \\ Lacey Samuels ${ }^{2}$ and Anthony D.M. Glass ${ }^{3}$ \\ Department of Botany, University of British Columbia, 3529-6270 University Boulevard, \\ Vancouver, B.C. V6T 124, Canada \\ Additional index words. Uncinula necator, Otis vinifera, silica, pathogen resistance
}

\begin{abstract}
The effect of root or leaf applications of soluble Si on severity of grape (Vitis vinifera L.) powdery mildew [Uncinula necator (Schwein) Burrill] was determined. On potted plants, root-feeding at $1.7 \mathrm{~mm} \mathrm{Si} \mathrm{had} \mathrm{no} \mathrm{effect} \mathrm{on}$ disease severity, but foliar sprays at $17 \mathrm{~mm} \mathrm{Si} \mathrm{substantially} \mathrm{reduced} \mathrm{the} \mathrm{number} \mathrm{of} \mathrm{mildew} \mathrm{colonies} \mathrm{that} \mathrm{developed}$ on inoculated leaves. Scanning electron micrographs showed that, on Si-sprayed leaves, hyphae did not develop in areas where thick $\mathrm{Si}$ deposits were present on the leaf surface; and where surface deposits were not present, Si was translocated laterally through the leaf and surrounded the appressoria. Leaves on plants that were fed Si via roots showed a similar deposition of $\mathrm{Si}$ surrounding the appressoria. On water-sprayed leaves and leaves from untreated plants, internal deposition of Si was more variable and generally less than on Si-sprayed or root-fed plants. Conidia germination and germtube development on agar media were weakly promoted by the presence of Si. Reduced severity of grape mildew by Si sprays may be partly due to a physical barrier to hyphal penetration and to a resistance response involving the lateral movement of $\mathrm{Si}$ and its deposition within the leaf at fungal penetration sites.
\end{abstract}

In monocot crops, the association between $\mathrm{Si}$ and reduced severity of fungal diseases has been known for some time. Germar (1934) reported that wheat (Triticum aestivum L.) plants supplied with $\mathrm{Si}$ are more resistant to powdery mildew (Erysiphe graminis f. sp. hordei) than control plants. Since then, Si has been implicated in several other monocot disease resistance responses, including sorghum (Sorghum vulgare Pert.) resistance to anthracnose (Colletotricum graminicolum) (Narwal, 1973), barley (Hordium vulgare L.) and wheat resistance to powdery mildew (E. graminis f. sp. hordei) (Jiang et al., 1989; Kunoh and Ishizaki, 1976; Leusch and Buchenauer, 1989; Sargent and Gay, 1977), and rice (Oryza sativa L.) resistance to blast (Piricularia oryzae Cav.), brown spot (Bipolaris oryzae Shoemaker) and sheath blight (Corticium sasakii Shiriai) (Aleshin et al., 1986; Datnoff and Snyder, 1991; Mathai et al., 1978; Volk et al., 1958). The exact role silica plays in enhancing disease resistance in monocots is as yet undetermined, but localized deposits of Si have been found in host tissue surrounding fungal haustoria (Kunoh and Ishizaki, 1976; Sargent and Gay, 1977).

In dicots, less attention has been paid to the association between $\mathrm{Si}$ and resistance to fungal infection. Although Wagner (1940) reported that cucumber powdery mildew severity was reduced by supplying plants with $\mathrm{Si}$, current interest in this phenomenon was not spawned until the mid-1980s, when it was reported that the natural incidence of powdery mildew was reduced by feeding $\mathrm{Si}$ to solution-cultured cucumbers (Adatia and Besford, 1986; Miyake and Takahashi, 1983). The reduction in

Received for publication 5 Nov. 1991. Accepted for publication 6 May 1992. Agriculture Canada Agassiz Research Station Contribution no. 461. We thank Carol Koch, Daisy May Vianzon, Ed Lynn, and Kelly Mack for their excellent technical assistance and Bill Lanterman, Agriculture Canada Plant Quarantive Station, Saanitchton, B.C., for plant material. Mention of a trademark or proprietary product does not imply endorsement of the product named or criticism of other products that may also be suitable. The cost of publishing this paper was defrayed in part by the payment of page charges. Under postal regulations, this paper therefore must be hereby marked advertisement solely to indicate this fact.

${ }^{1}$ Research Scientist.

${ }^{2}$ Postdoctoral Fellow.

${ }^{3}$ Professor. cucumber powdery mildew with $\mathrm{Si}$ feeding has since been shown to be coincident with an accumulation of $\mathrm{Si}$ in the leaves (Menzies et al., 1991a). Using scanning electron microscopy (SEM) and energy dispersive X-ray analysis (EDX), Samuels et al. (1991a) showed that infection of Si-fed cucumber plants results in a deposition of $\mathrm{Si}$ in host cell walls at hyphal penetration sites. Associated with this response are a reduction in haustoria formation and an increase in phenolic production (Menzies et al., 1991b). Timed Si-feeding studies have also found that soluble $\mathrm{Si}$ polymerizes quickly in cucumber leaves and that disease development is suppressed only if $\mathrm{Si}$ is present in soluble form (Samuels et al., 1991b). To minimize disease development, Si must therefore be provided continuously in the nutrient feed.

Until recently, studies associating reduced disease severity with $\mathrm{Si}$ in cucumber and monocot crops have involved root absorption of $\mathrm{Si}$ from soil or culture media. In a concurrent study, it was shown that $\mathrm{Si}$ was effective in reducing powdery mildew severity on cucumber, muskmelon, and zucchini squash when applied as a foliar spray (Menzies et al., 1992). Whether

Table 1. Effect of $\mathrm{Si}$ and $\mathrm{K}_{2} \mathrm{HPO}_{4}$ sprays on powdery mildew colony development on grape leaves.

\begin{tabular}{|c|c|c|c|c|}
\hline $\begin{array}{l}\text { Days after } \\
\text { inoculation }\end{array}$ & Spray & $\begin{array}{c}\text { Concn } \\
(\mathrm{mm})\end{array}$ & Colonies $^{2}$ & SE \\
\hline \multirow[t]{4}{*}{13} & Water & & $10 a^{y}$ & 2.2 \\
\hline & $\mathrm{Si}$ & 17 & $3 \mathrm{~b}$ & 0.9 \\
\hline & $\mathrm{K}_{2} \mathrm{HPO}_{4}$ & 3.7 & $11 \mathrm{a}$ & 3.0 \\
\hline & $\mathrm{K}_{2} \mathrm{HPO}_{4}$ & 11.0 & $11 \mathrm{a}$ & 0.9 \\
\hline \multirow[t]{4}{*}{16} & Water & & $15 \mathrm{a}$ & 3.3 \\
\hline & $\mathrm{Si}$ & 17 & $6 \mathrm{~b}$ & 0.8 \\
\hline & $\mathrm{K}_{2} \mathrm{HPO}_{4}$ & 3.7 & $17 \mathrm{a}$ & 3.1 \\
\hline & $\mathrm{K}_{2} \mathrm{HPO}_{4}$ & 11.0 & $17 \mathrm{a}$ & 2.8 \\
\hline \multirow[t]{4}{*}{19} & Water & & $18 \mathrm{a}$ & 4.1 \\
\hline & $\mathrm{Si}$ & 17 & $6 \mathrm{~b}$ & 0.9 \\
\hline & $\mathrm{K}_{2} \mathrm{HPO}_{4}$ & 3.7 & $21 \mathrm{a}$ & 4.4 \\
\hline & $\mathrm{K}_{2} \mathrm{HPO}_{4}$ & 11.0 & $20 \mathrm{a}$ & 2.0 \\
\hline
\end{tabular}

${ }^{2}$ Mean number of colonies per leaf from four plants, two leaves per plant.

'Mean separation within each day by Duncan's multiple range test, $P$ $=0.05$. 
$\mathrm{Si}$ will enhance disease resistance in noncucurbit dicots when applied either via the roots or as a foliar spray is unknown. Foliar application of $\mathrm{Si}$, if effective, may provide a practical means of boosting plant disease resistance in field-grown crops.

In grape culture, powdery mildew caused- by Uncinula necator is one of the most common and difficult-to-control diseases. To our knowledge, $\mathrm{Si}$ has not yet been associated with disease resistance in grape or any other noncucurbit dicot. The objective of this study was to assess the effectiveness of soluble $\mathrm{Si}$, applied either as a foliar spray or to the roots, in reducing severity of grape powdery mildew.

\section{Materials and Methods}

Effects of foliar applications of $\mathrm{K}$ and $\mathrm{PO}_{4}$. In hydroponic feeding studies of cucumber, soluble $\mathrm{Si}$ solutions have been prepared by diluting a predissolved potassium silicate such as Kasil \#6 (National Silicates, Toronto, Canada) (Menzies et al., 1991a, 1991b; Samuels et al., 1991a, 1991b). Such a solution is extremely basic and must be $\mathrm{pH}$ neutralized before it is ap-

Table 2. Effects of root and spray applications of $\mathrm{Si}$ on the number of powdery mildew colonies on grape leaves.

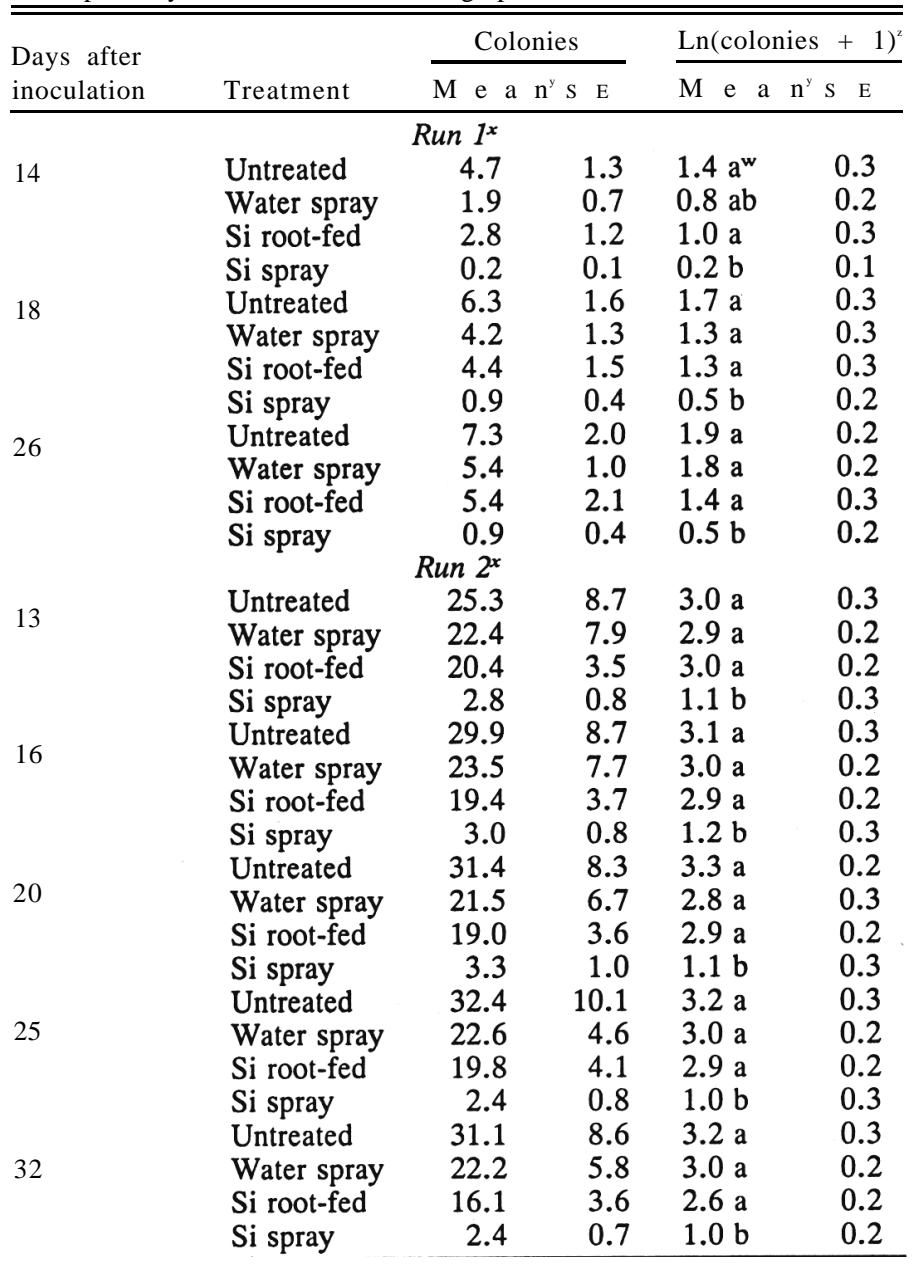

${ }^{2} \mathrm{Ln}$-transformation to provide homogeneity of variance.

${ }^{y}$ Mean number of colonies per leaf from nine plants, two leaves per plant.

${ }^{x}$ Run 1 and Run 2 refer to the first and second replicate runs of the experiment.

"Mean separation of In-transformed counts within each run of the experiment and day by Duncan's multiple range test, $P=0.05$. plied to plants. If $\mathrm{H}_{3} \mathrm{PO}_{4}$ is used, the solution contains $0.61 \mathrm{~mol}$ $\mathrm{K}$ and $0.33 \mathrm{~mol} \mathrm{PO}_{4} / \mathrm{mol} \mathrm{Si}$. Ideally, nutrient feed solutions effective in reducing powdery mildew incidence in cucumber should contain at least $1.7 \mathrm{~mm} \mathrm{Si}(100 \mathrm{ppm} \mathrm{SiO}$ ) (Menzies et al., 1991a). The Si foliar spray used throughout this study was prepared with $\mathrm{Si} 10$ times more concentrated, containing $\mathrm{Si}, \mathrm{K}$, and $\mathrm{PO}_{4}$ at 17,10 , and $5.5 \mathrm{~mm}$, respectively. In this experiment, sprays of $\mathrm{K}_{2} \mathrm{HPO}_{4}$ at two concentrations were compared with the $\mathrm{Si}$ spray to determine whether $\mathrm{K}$ and $\mathrm{PO}_{4}$ affect mildew severity.

Sixteen rooted woody cuttings of the grape rootstock hybrid LN33 were potted in sawdust and spaced evenly on greenhouse benches to provide $0.5 \mathrm{~m}^{2} /$ plant. Treatments were applied after 10 weeks of growth under $\approx 30 \mathrm{C}$ day maximum/18C night minimum, during which the plants sprouted between five and seven shoots that grew to $\approx 10$ nodes each. Watering was as needed with a nutrient solution prepared with reverse osmosis (RO) water to contain minimal $\mathrm{Si}$. The solution contained (mм): 13 $\mathrm{N} \mathrm{O}_{3}, 1.5 \mathrm{H}_{2} \mathrm{P} \mathrm{O}_{4}, 7.0 \mathrm{~K}, 0.08 \mathrm{Si}$, plus micronutrients.

Four spray solutions were prepared using RO water: a 17m M Si solution; two $\mathrm{K}_{2} \mathrm{HPO}_{4}$ solutions $\mathrm{pH}$ neutralized with $\mathrm{H}_{3} \mathrm{P} \mathrm{O}_{4}$; and a water control. The $\mathrm{K}_{2} \mathrm{HPO}_{4}$ solutions were prepared at $3.7 \mathrm{~mm}\left(\mathrm{~K}\right.$ and $\mathrm{PO}_{4}$ at 7.4 and $5.5 \mathrm{~mm}$, respectively) and $11 \mathrm{~mm}\left(\mathrm{~K}\right.$ and $\mathrm{PO}_{4}$ at 22 and $16 \mathrm{~mm}$, respectively). A drop of Tween 20 was added to each liter of solution. The sprays were applied, until drip, to the upper surface of two mature leaves on each of four randomly chosen vines. Twenty-four hours later, the leaves were inoculated with $U$. necator conidia. The conidia were collected $1 \mathrm{~h}$ before inoculation by shaking mature colonies on infected grape leaves into a flask of Fluorinert (FC-43; 3M Canada, London, Ont.). The number of viable conidia present was determined using a haemocytometer. The Fluorinert suspension was sprayed onto the upper surfaces of the leaves to provide inoculum at 500 conidia per leaf. Colonies became visible and were counted 13 days after inoculation. Colonies were counted again 2 and 5 days later. Duncan's multiple range test was used to separate treatment means of counts for each day.

Si foliar and root applications. Thirty-six potted LN33 grape plants were cultivated as described above, except that from the time of planting, nine randomly chosen vines were watered, as needed, with the standard nutrient solution plus $1.7 \mathrm{~mm} \mathrm{Si}$ (SiR). All other vines were watered with the low-Si nutrient solution. Each vine sprouted between four and six shoots that were allowed to grow without pruning or training through most of the study. Foliar treatments were applied when each plant had a shoot with at least six fully expanded leaves. The treatments were: an untreated control; a RO water spray; and a $17 \mathrm{~mm} \mathrm{Si}$ spray prepared as described above. Each foliar treatment was assigned to nine randomly selected vines receiving the low-Si nutrient solution. A single shoot with at least six leaves was chosen on each plant, and foliar sprays were applied until drip to upper surfaces of the fifth and sixth leaves from the shoot tip, counting only leaves with laminas $>3 \mathrm{~cm}$ long. Treated leaves and similarly selected leaves on root-fed and untreated plants were marked with a felt-tip pen for identification. Marked leaves were inoculated as described above $24 \mathrm{~h}$ after foliar treatments had been applied.

Eleven days after inoculation, the first colonies appeared on inoculated leaves. Sporulating colonies were counted on all marked leaves at 3, 7, and 15 days after the first colonies were detected. The diameters of all colonies were measured 9 days after colonies first appeared. 
The spray treatments were reapplied to the fifth and sixth leaves on another developing shoot on the same plants 18 days after first spraying. These and similar leaves on the untreated and $\mathrm{Si}$ root-fed plants were marked and inoculated as described above. At the time of the second inoculation, sporulating colonies were present on leaves inoculated previously on the same plants, but no visible colonies appeared on the second set of leaves until 10 days later. Counts of sporulating colonies were made at 3, 6, 10, 15, and 22 days after the first colonies were detected. Most shoots on the vines were trimmed to $\approx 20$ leaves just before the fourth count, but shoots with marked leaves were left untrimmed.

Treatment means for colony diameters and colony counts taken each day for each run of the experiment were separated by Duncan's multiple range test. Colony development over time was fit to the exponential function, $y=b_{0}\left(1-e^{(b 1 x)}\right)$, using the NLIN procedure of SAS statistical software (SAS Institute, Cary, N.C.).

Leaf Si distribution. Young colonies of $U$. necator were identified on some leaves of all treatments 10 days after inoculation of each replicate run of the Si-R and foliar spray experiments. Leaf sections were sampled by excising with a razor blade 1$\mathrm{c} \mathrm{m}^{2}$ areas containing the colonies. At least three leaves from each treatment were sampled in each run of the experiment. The excised leaf sections were immediately transferred to aluminum or carbon SEM stubs that had been coated with double sticky tape. The samples were air dried, rather than fixed, to prevent the redistribution of elements within the tissues, and then sputter-coated with gold. Uncoated samples were also tested as a control for this step to verify that gold did not interfere with the $\mathrm{X}$-ray analysis for Si.

Energy-dispersive EDX was performed using a Cambridge 250 scanning electron microscope (Cambridge Instruments, Cambridge, U.K.) operated at $20 \mathrm{kV}$, equipped with a Link An 10000 X-ray analyzer (Link Systems, Highwicombe, U.K.), and interfaced with a Kontron Image Processing System (Kontron Bildanalyse, Munich). X-ray spectra were gathered, and the elements of interest were designated as windows consisting

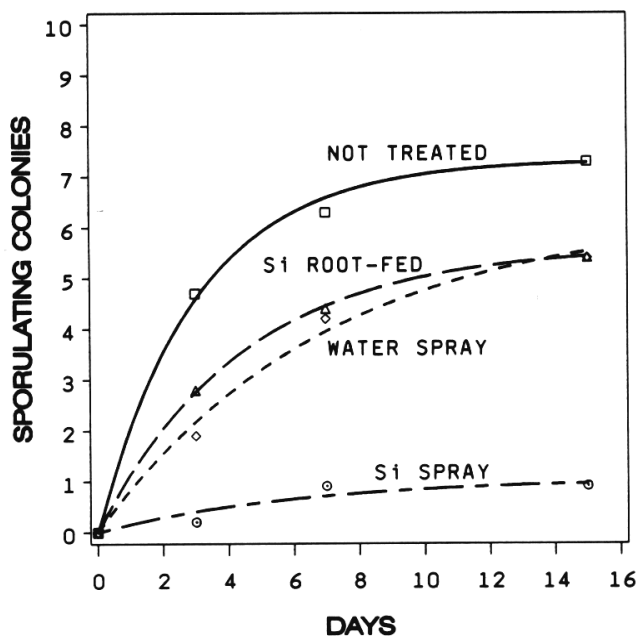

Fig. 1. Mildew colony development over time following $\mathrm{Si}$ treatments (first run). Each point represents the mean number of colonies per leaf from nine plants. Curves were fit to the function $y=b_{0}(1$ - $\left.\mathrm{e}^{(\mathrm{b} 1 \mathrm{x})}\right)$. Untreated: $\mathrm{b}_{0}=7.33, \mathrm{~b}_{1}=-0.327, R^{2}=0.64$. Water spray: $b_{0}=6.27, b_{1}=-0.142, R^{2}=0.65$. Si root-fed: $b_{0}=$ $5.62, \mathrm{~b}_{1}=-0.225, R^{2}=0.46$. Si spray: $\mathrm{b}_{0}=1.04, \mathrm{~b}_{1}=-0.163$, $R^{2}=0.41$.

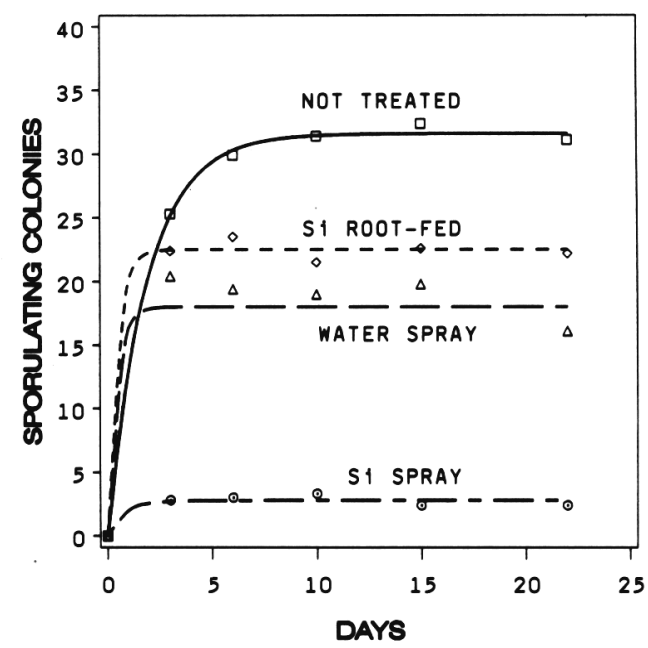

Fig. 2. Mildew colony development over time following Si treatments (second run). Each point represents the mean number of colonies per leaf from nine plants. Curves were fit to the function $\mathrm{y}=$ $\mathrm{b}_{0}\left(1-\mathrm{e}^{(\mathrm{b} \mid \mathrm{x})}\right)$. Untreated: $\mathrm{b}_{0}=31.6, \mathrm{~b}_{1}=-0.530, R^{2}=0.59$. Water spray: $\mathrm{b}_{0}=22.5, \mathrm{~b}_{1}=-2.27, R^{2}=0.59$. Si root-fed: $\mathrm{b}_{0}$ $=17.99, \mathrm{~b}_{1}=-2.39, R^{2}=0.76$. Si spray: $\mathrm{b}_{0}=2.77, \mathrm{~b}_{1}=$ $-1.27, R^{2}=0.58$.

of seven channels of $0.02 \mathrm{KeV}$. The location of each element was mapped by the image analysis computer by positioning the beam of the SEM on an individual pixel for a dwell time of 10 msec over a raster of $256 \times 256$ pixels. When X-rays from the element of interest were found in the pixel, they were indicated by a bright spot on the quadrant of the four-channel map corresponding to that element, Distributions of $\mathrm{Si}, \mathrm{K}$, and $\mathrm{Ca}$ were generated by overlaying the appropriate quadrant of the fourchannel map on the original SEM image.

Conidia germination and germtube development. To determine whether dissolved $\mathrm{Si}$ inhibits conidia germination and germtube growth in $U$. necator, conidia were germinated on $2 \%$ agar media amended with $\mathrm{Si}$ at $0,1.7,8.4$, and $17 \mathrm{~mm}$. Each treatment was replicated four times in individual petri dishes. Conidia were collected by pressing two sporulating colonies onto the agar surface in each dish. Percent germination and average germtube length were determined by examining 100 conidia per dish after $24 \mathrm{~h}$ of incubation at 20C. This experiment was repeated once.

\section{Results and Discussion}

In the experiment to determine whether the $\mathrm{K}$ and $\mathrm{PO}_{4}$ in the $\mathrm{Si}$ spray affected powdery mildew severity, there were no differences in the number of $U$. necator colonies that developed on water-sprayed and $\mathrm{K}_{2} \mathrm{HPO}_{4}$-sprayed leaves (Table 1). At the last count, made 19 days after inoculation, colony development on Si-sprayed leaves was $33 \%$ of that on water-sprayed leaves. This result indicates the severity of $U$. necator infection is unaffected by $\mathrm{K}$ and $\mathrm{PO}_{4}$ together on the leaf surface but is reduced by the presence of $\mathrm{Si}$. We also observed (not quantified) that older leaves developed fewer colonies.

In both replicate runs of the foliar spray and $\mathrm{Si}-\mathrm{R}$ experiment, the final colony count variance differed among treatments and was directly related to the mean. A In-transformation [In(colonies $+1)$ ] provided variance homogeneity so that mean separation could be performed. Colony development on SGR plants did not differ from that on untreated or water-sprayed controls (Ta- 

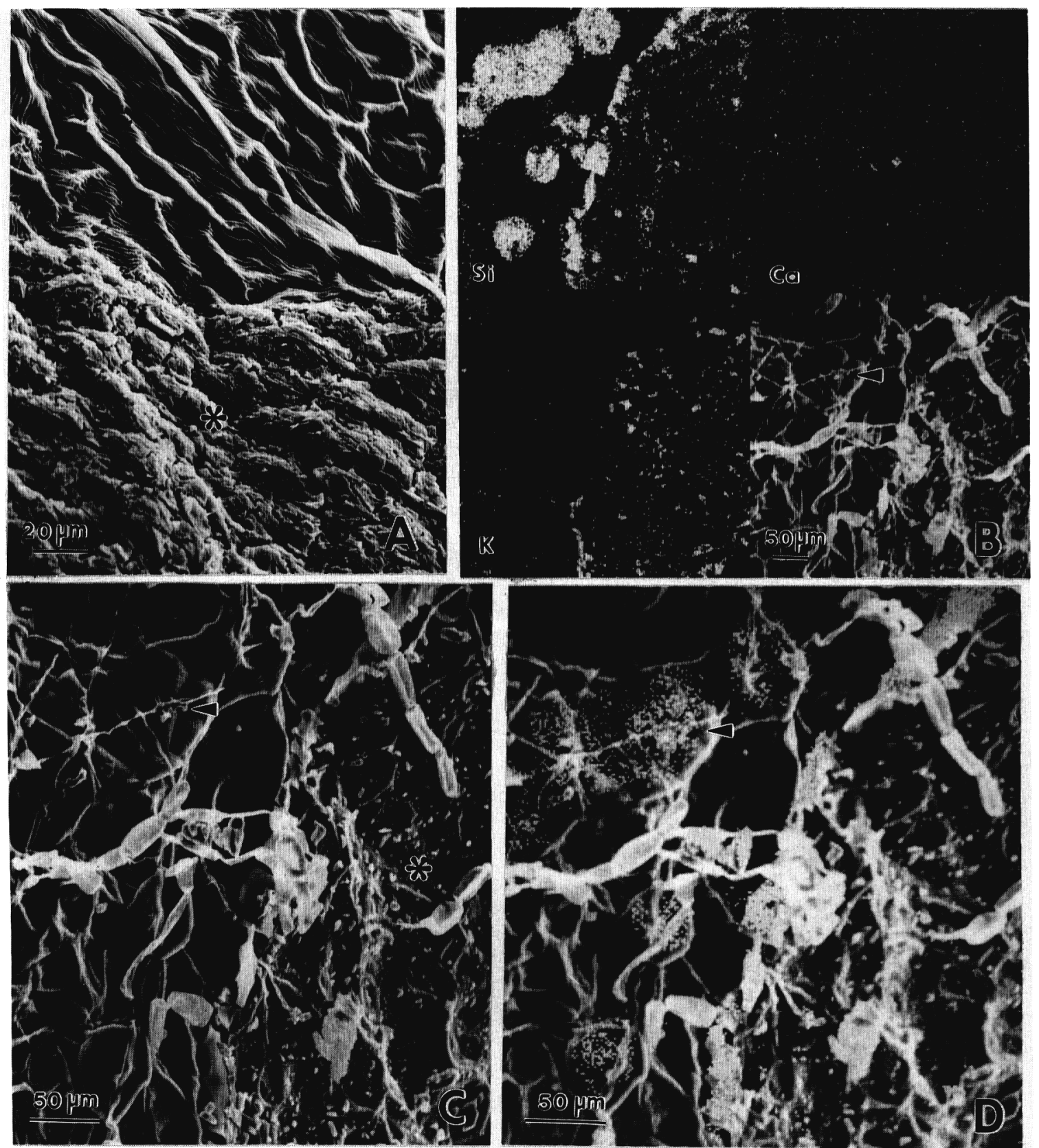

Fig. 3. SEM images of Si-sprayed leaves. (A) $72 \mathrm{~h}$ after spray application showing thick potassium silicate layer (bottom asterisk) that obscures normal grape leaf cuticle texture (top of image). (B) Four-channel X-ray map shows distribution of elements of interest in grape leaf 10 days after inoculation. Quadrats: Upper left, $\mathrm{Si}$; upper right, $\mathrm{Ca}$; lower left, $\mathrm{K}$; lower right, SEM image of region scanned. Right side of field shows edge of spray deposit. (C) Enlargement of SEM image of area mapped in (B). On Si spray deposit to right (asterisk), conidia have not produced hyphae. On the area without apparent deposit to left, abundant hyphae extend across the leaf surface. Modified areas of host cell wall around lobed appressoria (arrow) are not as collapsed as surrounding cells following air drying. (D) Silicon distribution shown by overlay of $\mathrm{Si}$ map on original SEM image. Dots indicate regions of high $\mathrm{Si}$ around appressoria (arrow).

ble 2). However, the $\mathrm{Si}$ foliar spray reduced the number of colonies to $\approx 14 \%$ and $9 \%$ of that of control leaves in the first and seconds runs of the experiment, respectively (Table 2). Colony diameter averaged $4.6 \mathrm{~mm}$ and did not differ among treatments.

The stability of the infection levels achieved in the foliar spray and Si-R experiment is shown in Figs. 1 and 2. Colony development over time for all treatments in both runs of the experiment followed the exponential relationship with time, y $=b_{o}\left(1-e^{(b \mid x)}\right)$, where $y$ is the number of sporulating colonies $\mathrm{x}$ days from the onset of colony development, $\mathrm{b}_{\mathrm{o}}$ is the asymptotic maximum predicted colony count, and $b_{1}$ is a negative constant related to the initial rate of colony development. Final colony counts were higher and maximum counts were achieved in less time for all treatments in the second run (Fig. 2) of the experiment than in the first run (Figs. 1 and 2), possibly due to higher mean leaf temperatures resulting from fewer cloudy days during the second run. However, early in both runs, colony counts had plateaued and were close to the predicted maxima. The reduction in the colony count due to the $\mathrm{Si}$ spray was thus 

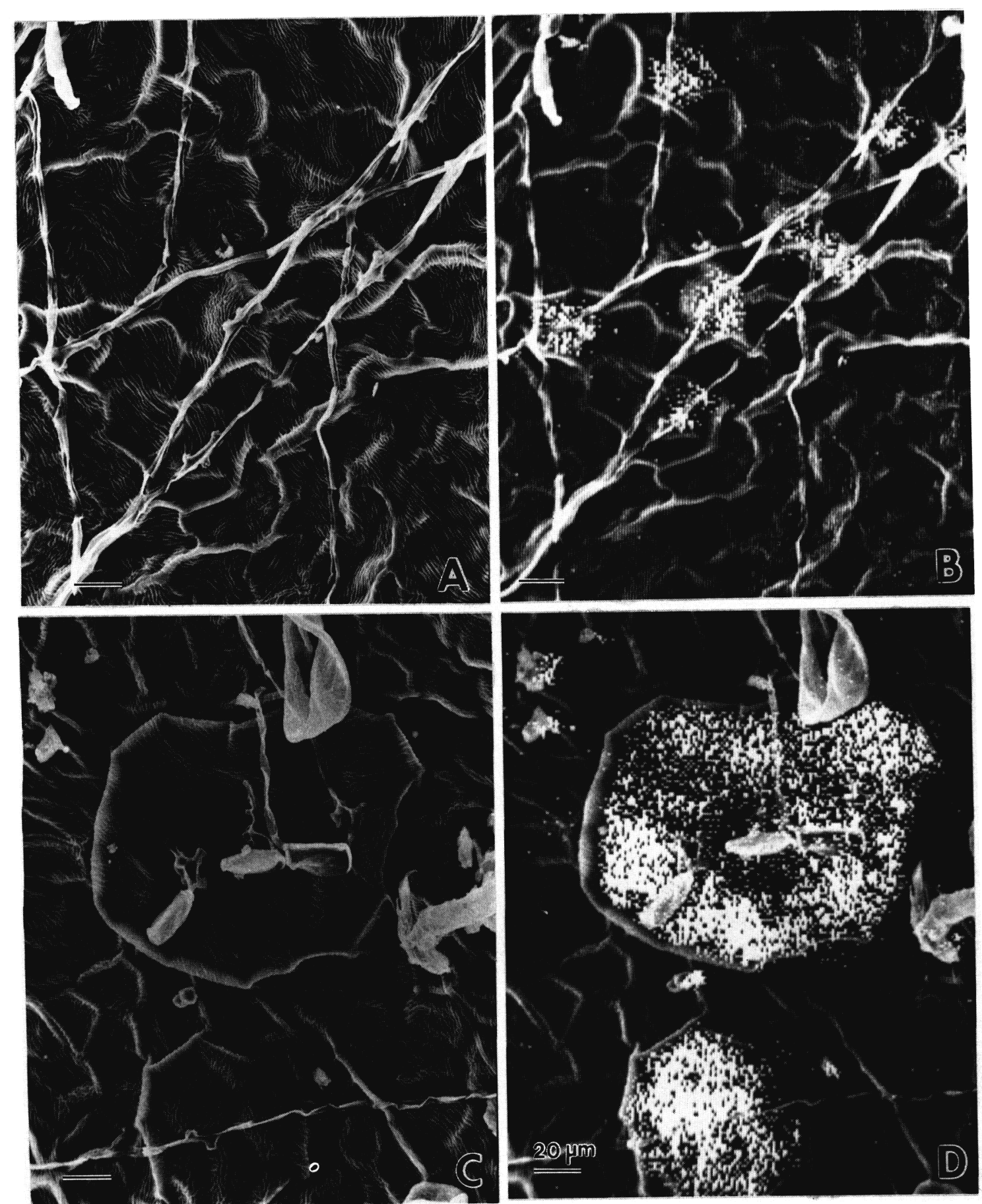

Fig. 4. SEM images of nonsprayed leaves 10 days after inoculation. (A) Leaf from untreated plant. Fungal hyphae on leaf display lobed appressoria surrounded by modified host wall. (B) Si distribution on leaf shown in (A). White dots indicate regions of high Si. The amount of $\mathrm{Si}$ in untreated leaves varied from not detectable to similar to Si-treated. (C) Leaf from Si-R plant. Germinating conidia are surrounded by modified host cell wall. Below, mature hyphae is seen with lobed appressoria. (D) Si distribution of leaf shown in (C). Regions of modified host cell wall contain high $\mathrm{Si}$ (white dots). All bars $=20 \mu \mathrm{m}$.

stable and unlikely the result of a slowing of fungal development that delayed colony appearance.

Whitish spots of dried solution were observed on Si-sprayed leaves. Under the SEM, the normal lined texture of the leaf cuticle was obscured by circular areas where a thick coating had formed (Fig. 3A). Using X-ray mapping, it was confirmed that these droplets consisted of potassium silicate (Fig. 3B).

Abundant hyphae of $U$. necator extended across the leaf sur- face, and the lobed appressoria characteristic of this genus were visible (Fig. 3C). These lobed appressoria are the initiation sites of haustoria (Braun, 1987). In areas where spray droplets had been deposited, conidia were present but had not produced hyphae (Fig. 3C). In areas remote from the droplets, the lobed appressoria were surrounded by a region of modified host cell wall, and these areas were enriched in Si (Fig. 3D).

Water-sprayed leaves and leaves from untreated plants were 


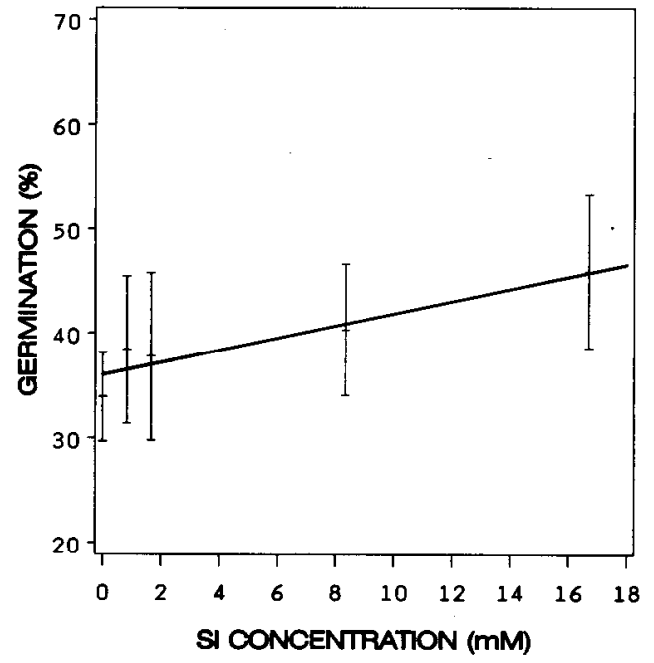

Fig. 5. Germination of Uncinula necator conidia in response to $\mathrm{Si}$ concentration in an agar medium. Means \pm SE of four replicate cultures, 100 conidia per culture. Regression: $\mathrm{y}=36.0+0.59 \mathrm{x}, R^{2}$ $=0.13, P=0.02$.

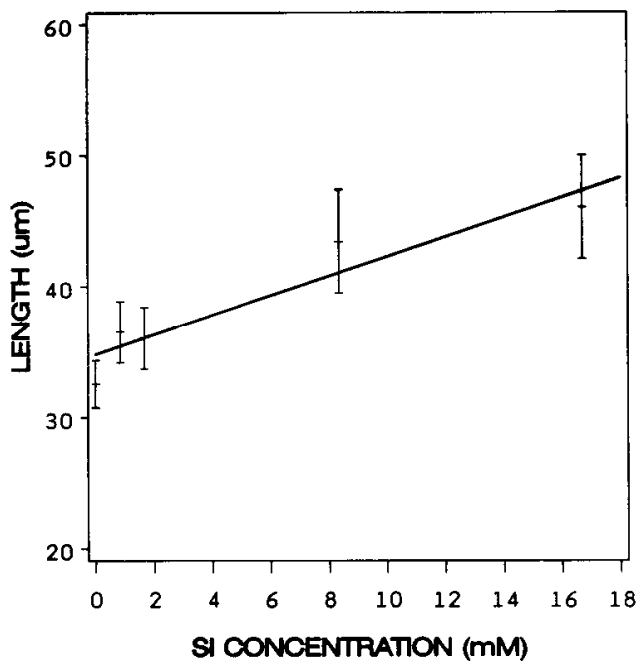

Fig. 6. Length of germ tubes from Uncinula necator conidia in response to $\mathrm{Si}$ concentration in an agar medium. Means \pm SE of conidia on four replicate cultures, 100 conidia per culture. Regression: $\mathrm{y}=6.96+0.15 \mathrm{x}, R^{2}=0.51, P=0.0001$.

indistinguishable under the SEM. In both cases, abundant fungal hyphae with lobed appressoria spread across the leaf surface (Fig. 4A). Some leaf samples of both treatments contained Si in the region surrounding the appressoria (Fig. 4B), although their presence was quite variable.

In leaves from plants that had been root-fed $\mathrm{Si}$, the appressoria were surrounded by $\mathrm{Si}$ in all samples tested (Fig. 4, C and D). Although these leaves showed no reduction in the number of colonies that developed relative to leaves from untreated plants, they showed extensive silicification of host tissue surrounding the fungal appressoria.

In cucumber, the extent of silicification in leaves depends on the availability of soluble $\mathrm{Si}$ as monosilicic acid in the soil or hydroponic solution (Samuels et al., 1991b). The reduced severity of grape powdery mildew with the $\mathrm{Si}$ spray and not with root-feeding may reflect a quantitative effect of $\mathrm{Si}$ that is not differentiated by the SEM-EDX technique. The extremely high concentration of $\mathrm{Si}$ sprayed on the leaves may have resulted in $\mathrm{Si}$ being absorbed at a level sufficient to enhance host resistance. Alternatively, the effectiveness of the Si spray may have been due primarily or in part to a barrier effect on the leaf surface. The thick potassium silicate deposits that coated a significant portion of the leaf cuticle may have prevented penetration by germinating conidia. In the areas of the leaf surface that had not been coated, fungal development was more extensive (Fig. $3 \mathrm{C})$. However, in these areas some of the $\mathrm{Si}$ deposited on the leaf surface was apparently absorbed and translocated laterally through the leaf, to where it surrounded the appressoria.

The possibility that infection was reduced by an inhibitory effect of $\mathrm{Si}$ on conidia germination or germtube development is not supported by the results of the germination study. Germination and germtube elongation were both weakly promoted by the presence of $\mathrm{Si}$ in the agar media (Figs. 5 and 6). Only a linear response to $\mathrm{Si}$ concentration up to $17 \mathrm{~mm}$ was detected, although the $R^{2}$ was low in each case (Figs. 5 and 6). These results do not preclude the possibility that dry potassium silicate deposits on a leaf surface inhibit germtube development or act as a physical barrier to penetration.

In this study, soluble $\mathrm{Si}$ applied to the leaves or roots of grape plants was absorbed and translocated to leaf tissue surrounding appressoria of $U$. necator. This result is similar to that found in studies with barley and cucumber, in which $\mathrm{Si}$ was absorbed only via the roots (Kunoh and Ishizaki, 1976; Samuels et al., 1991; Sargent and Gay, 1977). Silicon deposition at sites of fungal pathogen penetration may be a common component of the host-defense response in a variety of plant families. In grape, additional protection against $U$. necator infection may be provided by dry deposits of potassium silicate on the leaf surface.

\section{Literature Cited}

Adatia, M.H. and R.T. Besford. 1986. The effect of silicon on cucumber plants grown in recirculating nutrient solution. Ann. Bot. 58:343-351.

Aleshin, N.E., E.R. Avakyan, S.A. Dyankunchak, E.P. Aleshin, V.P. Baryshok, and M.G. Voronkov. 1986. Role of silicon in resistance of rice to blast (in Russian). Doklady Akademii Nauk SSSR 291:499502.

Braun, U. 1987. A monograph on the Erysiphales. L. Cramer Publishers, Berlin,

Datnoff, L.E. and G.H. Snyder. 1991. Effect of calcium silicate on blast and brown spot intensities and yields of rice. Plant Dis. 75:729732 .

Germar, B. 1934. Some functions of silicic acid in cereals with special reference to resistance to mildew (in German). Z. Pflanzenemähr Düng. Bodenk. 35:102-115.

Jiang, D., R.J. Zeyen, and V. Russo. 1989. Silicon enhances resistance of barley to powdery mildew (Erysiphe graminis f. sp. hordei). Phytopathology 79:1198. (Abstr.)

Kunoh, H. and H. Ishizaki. 1976. Accumulation of chemical elements around the penetration sites of Erysiphe graminis hordei on barley leaf epidermis. II. Level of silicon in papilla around the haustorial neck. Annu. Phytopathol. Soc. Jpn. 42:30-34.

Leusch, H.J. and H. Buchenauer. 1989. Effect of soil treatments with silica-rich lime fertilizers and sodium trisilicate on the incidence of wheat by Elysiphe graminis and Septoria nodorum depending on the form of N-fertilizer. J. Plant Dis. and Protection 96:154-172.

Mathai, G., P.V. Paily, and M.R. Menon. 1978. Effect of fungicides and silica in the control of sheath blight disease of rice caused by Corticum saskii (Shiriai). Agr. Res. J. Kerala 19:79-83.

Menzies, J.G., P.A. Bowen, D.L. Ehret, and A.D.M. Glass. 1992. Foliar applications of potassium silicate reduce severity of powdery mildew of cucumber, muskmelon, and zucchini squash. J. Amer. Soc. Hort. Sci. 117:902-905. 
Menzies, J.G., D.L. Ehret, A.D.M. Glass, T. Helmer, C. Koch, and F. Seyward. 1991a. The effects of soluble silicon on the parasitic fitness of Sphaerotheca fuliginea (Schlecht.: Fr.) Poll. on Cucumis sativus L. Phytopathology 81:84-88.

Menzies, J.G., D.L. Ehret, A.D.M. Glass, and A.L. Samuels. 1991 b. The influence of silicon on cytological interactions between Sphaerotheca fuliginea and Cucumis sativus. Physiol. \& Mol. Plant Pathol. 39:403-414.

Miyake, Y. and E. Takahashi. 1983. Effect of silicon on solution cultured cucumber plant. Soil Sci. Plant Nutr. Tokyo 29:71-83.

Narwal, R.P. 1973. Silica bodies and resistance to infection in jowar (Sorghum vulgare Pert.). Agra Univ. J. Res. 22:17-20.

Samuels, A.L., A.D.M. Glass, D.L. Ehret, and J.G. Menzies. 1991a. Distribution of silicon in cucumber leaves during infection by pow- dery mildew fungus (Sphaerotheca fuliginea). Can. J. Bot. 69:140146.

Samuels, A.L., A.D.M. Glass, D.L. Ehret, and J.G. Menzies. $1991 \mathrm{~b}$. Mobility and deposition of silicon in cucumber plants. Plant Cell \& Environ. 14:485-492.

Sargent, C. and J.L. Gay. 1977. Barley epidermal apoplast structure and modification by powdery mildew contact. Physiol. Plant Pathol. 11:195-205

Volk R.J., R.P. Kahn, and R.L. Weintraub. 1958. Silicon content of the rice plant as a factor influencing its resistance to infection by the blast fungus, Piricularia oryzae. Phytopathology 48:121-178.

Wagner, F. 1940. The significance of silicic acid for the growth of certain cultivated plants, their nutrient economy, and their susceptibility to genuine mildews (in German). Phytopathol. Z. 12:427-479. 